Check for updates

Cite this: RSC Adv., 2019, 9, 20169

\title{
Improved antibacterial performance using hydrogel-immobilized lysozyme as a catalyst in water $\dagger$
}

\author{
Yuemei Ye, (D) Stanislav Klimchuk, Mingwei Shang (D) and Junjie Niu (DD*
}

Silver nanoparticle-based catalysts are used extensively to kill bacteria in drinking water treatment. However secondary contamination and their high cost require scientists to seek alternatives with non-toxicity, high activity and low cost. In this article, we develop a new hydrogel-immobilized lysozyme (h-lysozyme) that shows excellent antibacterial performance, including high activity duration of up to 55 days, inhibition efficiency as high as $99.4 \%$, good recycling capability of up to 11 cycles, a wide temperature window and extremely low concentration. The immobilized lysozyme displayed greatly improved bacterial inhibition with both Gram-negative E. coli and Gram-positive B. subtilis, which enables broad antibacterial applications in various water systems. In parallel, the non-toxic structure and high stability of the hlysozyme without additional contamination make it a promising alternative to nanoparticle catalysts fur use in drinking water purification.

Received 1st April 2019

Accepted 14th June 2019

DOI: 10.1039/c9ra02464f

rsc.li/rsc-advances

can enhance the interaction area with biological contaminants and thus improve the removal efficiency at a low dosage. ${ }^{23-25}$

Here, we developed a new hydrogel-immobilized lysozyme (hlysozyme) to inhibit both Gram-negative (E. coli) and Grampositive (B. subtilis) bacterial growth in water. The immobilized lysozyme showed greatly improved activity, efficiency and recycling capability at room temperature. ${ }^{26-28}$ Owing to the strong bonding to the hydrogel and the porous structure of the cross-linked network, the antibacterial activity can be retained for a long period, e.g., months to years. ${ }^{28,29}$ The large surface area of the hydrogel also increases the bacterial molecular capture ability and thus increases the reaction opportunities with lysozyme. The excellent antibacterial performance along with the non-toxicity and low cost of the hlysozyme make it a promising alternative to replace the current silver particles in various water environments. ${ }^{30}$

As illustrated in Fig. 1a, a cross-linked porous hydrogel network is formed after the polarization of poly(ethylene glycol) methyl ether acrylate (PEGMA) monomer via UV irradiation. During this process, the lysozyme molecules are immobilized into the matrix. The largely exposed surface increases the interaction with bacteria while the porous structure provides sufficient space to capture bacteria (Fig. 1b). Then the presence of lysozyme introduces a catalytic reaction of the hydrolysis of peptidoglycan, which is the major component of the cell wall of most bacteria, as well as counteracting the osmotic pressure of the cytoplasm and binary fission during bacterial cell reproduction. Upon the reaction, the 1,4-beta-linkages between $N$-acetyl-Dglucosamine (NAG) and $N$-acetylmuramic acid (NAM) in peptidoglycan are broken (Fig. 1c). As a result, the hydrolyzed NAG and NAM molecules lead to the lysis of the bacteria. ${ }^{31,32}$ 

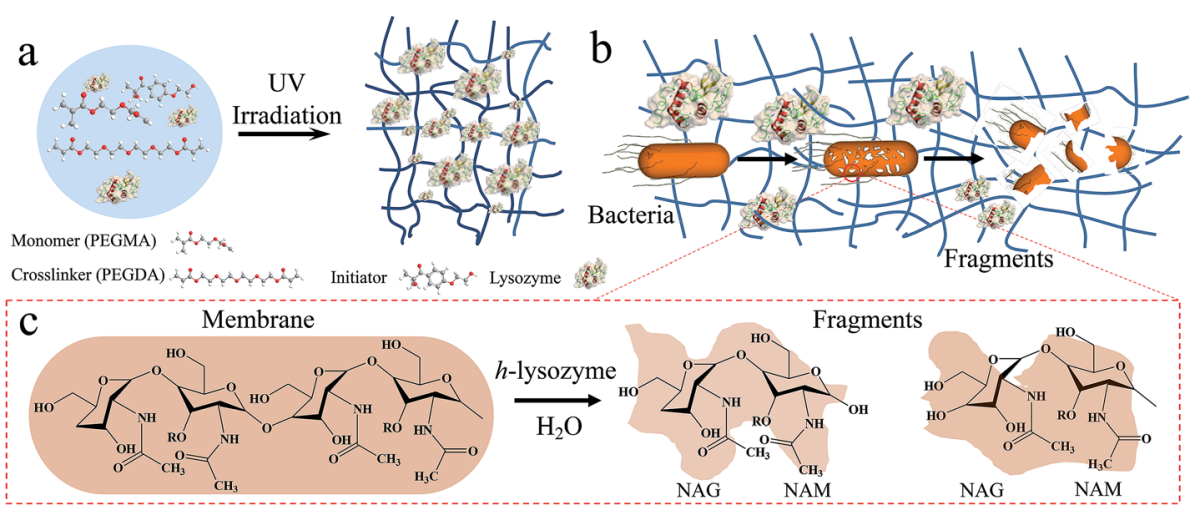

Fig. 1 Schematic diagram of hydrogel-immobilized lysozyme for antibacterial membrane modification. (a) The synthesis process, (b) the antibacterial process and (c) mechanism for killing bacteria.

A lysozyme with high activity and long stability is critical in antibacterial applications. It was found that the activity of lysozyme powder can remain for as long as two years. ${ }^{24,32}$ However, the activity of freestanding lysozyme will begin to be mitigated after being dispersed in water solution over a long time. ${ }^{33,34}$ In order to compare their activity, pure lysozyme powder, lysozyme in deionized (DI) water and h-lysozyme samples were checked by an ultraviolet (UV) spectrophotometer. In parallel, the samples under $-20{ }^{\circ} \mathrm{C},-4{ }^{\circ} \mathrm{C}$, room temperature (RT) and high temperatures of $60{ }^{\circ} \mathrm{C}, 65^{\circ} \mathrm{C}, 70{ }^{\circ} \mathrm{C}$, $80{ }^{\circ} \mathrm{C}$ were also measured.

Lysozyme activity was checked via a typical process using whole cells of Micrococcus lysodeikticus (ML) as substrate. ${ }^{35,36}$ The ML was dissolved in $0.1 \mathrm{M}$ phosphate buffer saline (PBS) solution $(\mathrm{pH}=6.24)$ at $\mathrm{RT}$. Then the concentration was adjusted until the measured UV density at $450 \mathrm{~nm}$ reached approximately 1.3 . The optical density (OA) evolution vs. time was recorded to calculate the activity:

$$
\text { Activity }\left(\mathrm{U} \mathrm{mg}^{-1}\right)=\Delta \mathrm{OD}_{450} \times 1000 / \mathrm{m}
$$

Here $\Delta \mathrm{OD}_{450}$ is the difference in optical density between $15 \mathrm{~s}$ and $75 \mathrm{~s}$, and $m$ is the mass $(\mathrm{mg}$ ) of lysozyme in $0.5 \mathrm{~mL}$ solution. The relative activity $(R \%)$ is obtained:

$$
R \%=\left(A_{\mathrm{i}} / A_{\mathrm{f}}\right) \times 100
$$

$A_{\mathrm{i}}$ stands for the measured activity of samples $\left(\mathrm{U} \mathrm{mg}^{-1}\right)$, and $A_{\mathrm{f}}$ represents the activity of freestanding lysozyme under same conditions.

It was found that h-lysozyme exhibits a $120-250 \%$ higher relative activity compared to lysozyme powder or lysozyme in water solution (less than $100 \%$ ) at RT (Fig. 2a), $-4{ }^{\circ} \mathrm{C}$ (Fig. 2b)
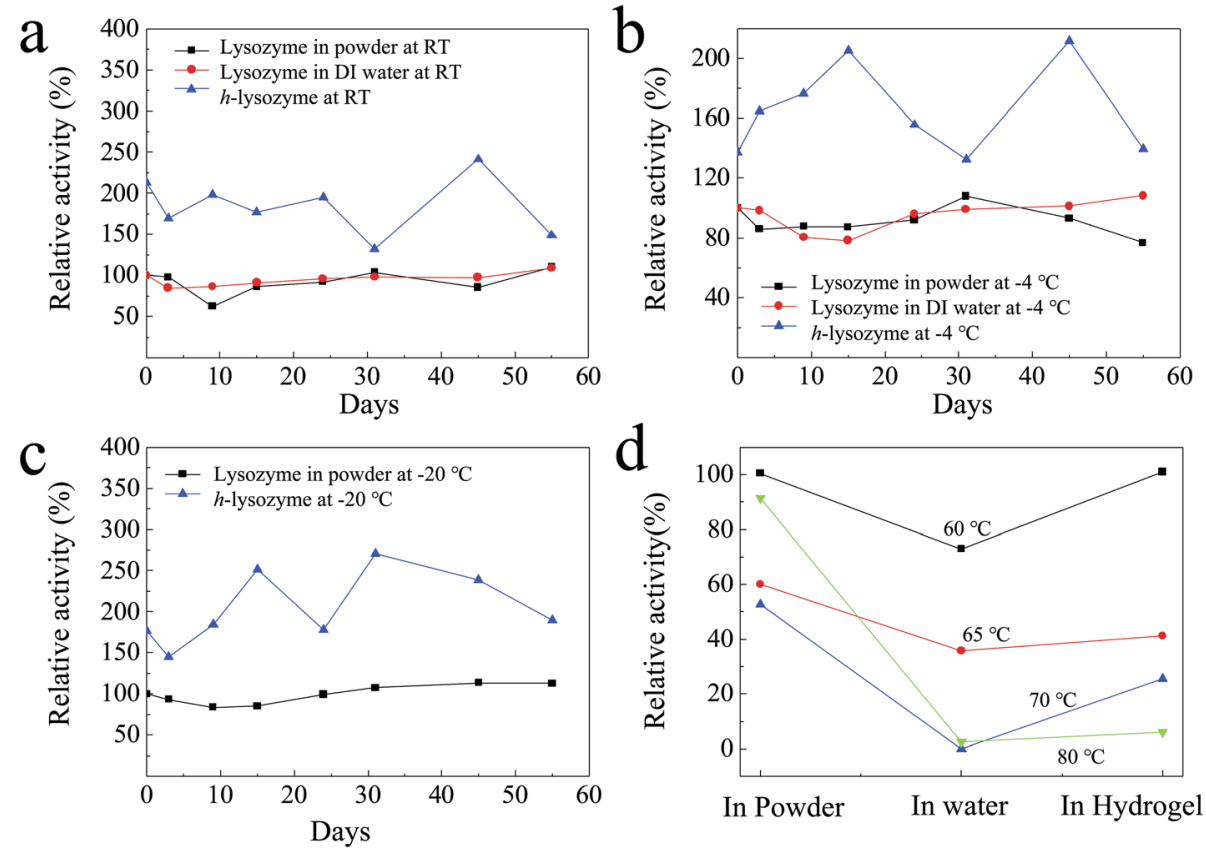

Fig. 2 The activity of h-lysozyme at (a) room temperature, (b) $-4{ }^{\circ} \mathrm{C},(\mathrm{c})-20^{\circ} \mathrm{C}$ and (d) high temperatures $\left(60^{\circ} \mathrm{C}, 65^{\circ} \mathrm{C}, 70^{\circ} \mathrm{C}, 80^{\circ} \mathrm{C}\right.$ ). 
and $-20{ }^{\circ} \mathrm{C}$ (Fig. 2c), respectively. Activity retention of up to 55 days was also recorded, indicating long-term stability. The fluctuation in the relative activity of the immobilized lysozyme is due to variations during sample preparation and UV measurement. At high temperature, $60{ }^{\circ} \mathrm{C}$, the h-lysozyme displayed similar activity to lysozyme powder while it was higher than that of lysozyme in water (Fig. 2d). A relatively high activity at higher temperatures of 65,70 and even $80{ }^{\circ} \mathrm{C}$ was still maintained, which demonstrates that h-lysozyme has good temperature tolerance. The hydrophilicity and large surface area of the PEG polymer based hydrogel attract plenty of bacteria, thus increasing the contact interface between the lysozyme and the ML molecules. As a result, a clearly improved activity under varying environments and temperatures was achieved.

The activity of the lysozyme in water at different concentrations was investigated. ${ }^{37,38}$ It was found that the lysozyme has

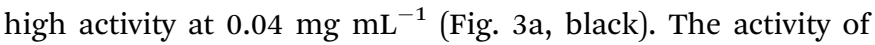
killing bacteria was decreased until an extremely low concentration of $0.0004 \mathrm{mg} \mathrm{mL}^{-1}$ (Fig. 3a, blue). The recycling activity of the pure lysozyme was studied, as shown in Fig. $3 \mathrm{~b}$. It can be observed that most activity was lost after two cycles, which was caused by the decreased contact between lysozyme and ML due to the accumulation of debris on the surface. As a comparison, the hydrogel network with large spaces enhances the accommodation of debris and dead bacteria, resulting in a large exposed interface remaining. The recycling activity of both lysozyme and h-lysozyme is shown in Fig. 3c. It can clearly be seen that the immobilized lysozyme showed a high activity of about $30 \%$ even after 11 cycles, while the activity of the lysozyme without immobilization dropped to less than $10 \%$ after 8 cycles. These results further confirm that the porous hydrogel framework delivers sufficient contact interface between the lysozyme and bacteria to drastically improve the activity. In addition, the cross-linked net matrix also expands the acceptance capacity of the killed bacteria, avoiding surface coverage causing a loss of activity, which is a generic problem in the traditional silver particle killing process.

The antibacterial capability was first tested by exposing the h-lysozyme to the Gram-negative bacterial module $E$. coli. In order to fast check the bacterial regrowth, a lysogeny broth media (LB) bacterial culture solution was used. ${ }^{39}$ Fig. 4a illustrates that UV-lysozyme (red) has the highest inhibition compared to hydrogel (blue), lysozyme (green) or control (black) samples. Specifically the $E$. coli was completely inhibited by lysozyme in the first 2 hours and showed a negligible increase even after 8 hours, which indicates a remarkable inhibition of $E$. coli. It should be noted that UV-irradiated lysozyme showed slightly improved inhibition due to the activation of lysozyme under irradiation. Interestingly, the hydrogel also displayed certain inhibition to E. coli growth (blue). Large amounts of bacteria were trapped inside the matrix and thus further growth was prevented due to the change of environment.

In order to mimic the real environment in drinking water, a solution with an initial $E$. coli concentration of $10^{5} \mathrm{CFU} \mathrm{mL}^{-1}$ was prepared and exposed to different samples of control ( $E$. coli), lysozyme, h-lysozyme and hydrogel, respectively. It was observed that h-lysozyme showed excellent $E$. coli inhibition
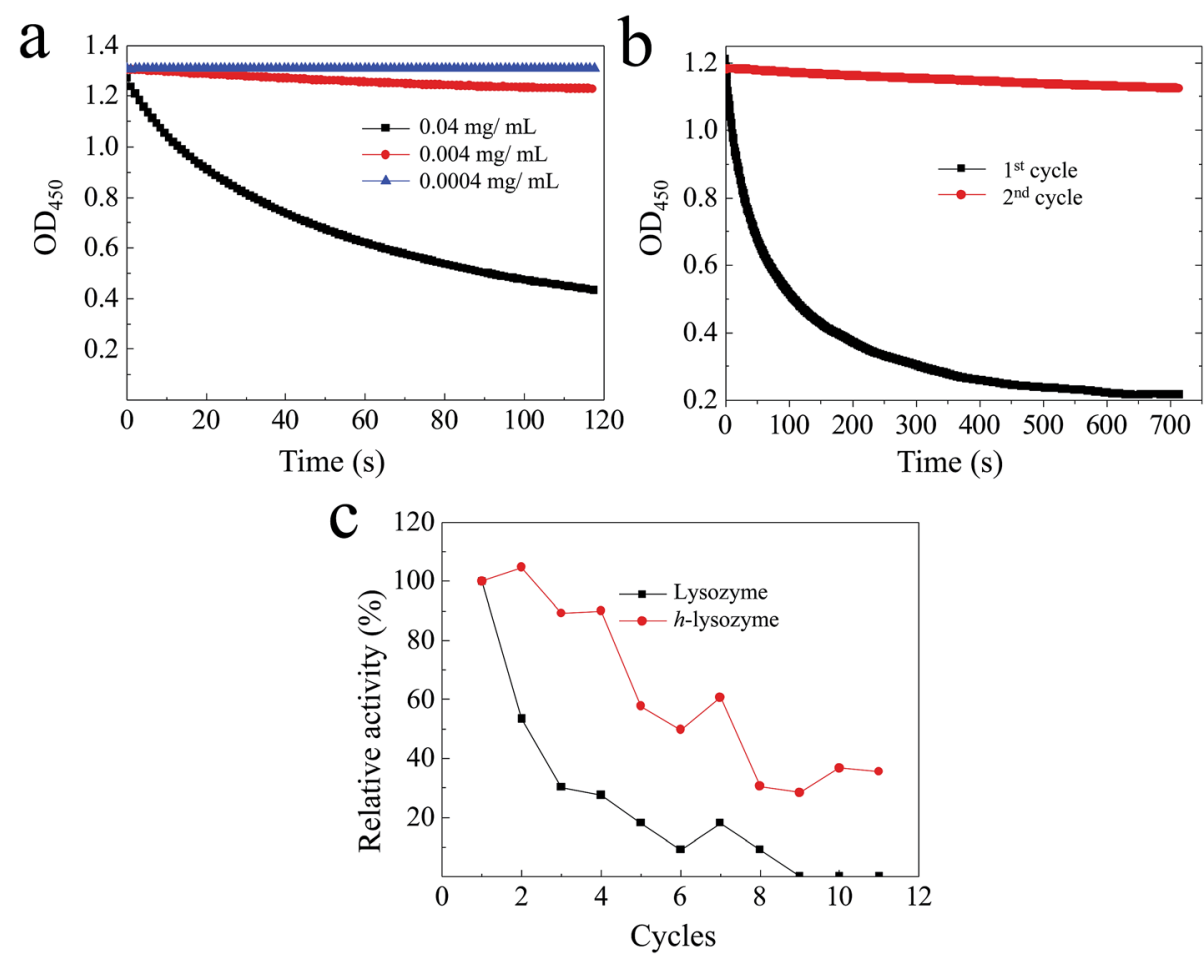

Fig. 3 The recycling activity test of lysozyme. (a) The activity of lysozyme with different concentrations at $\mathrm{OD}_{450}$. (b) The activity test of lysozyme in solution for two cycles. (c) The comparison of activity of pure lysozyme and h-lysozyme as function of cycles. 

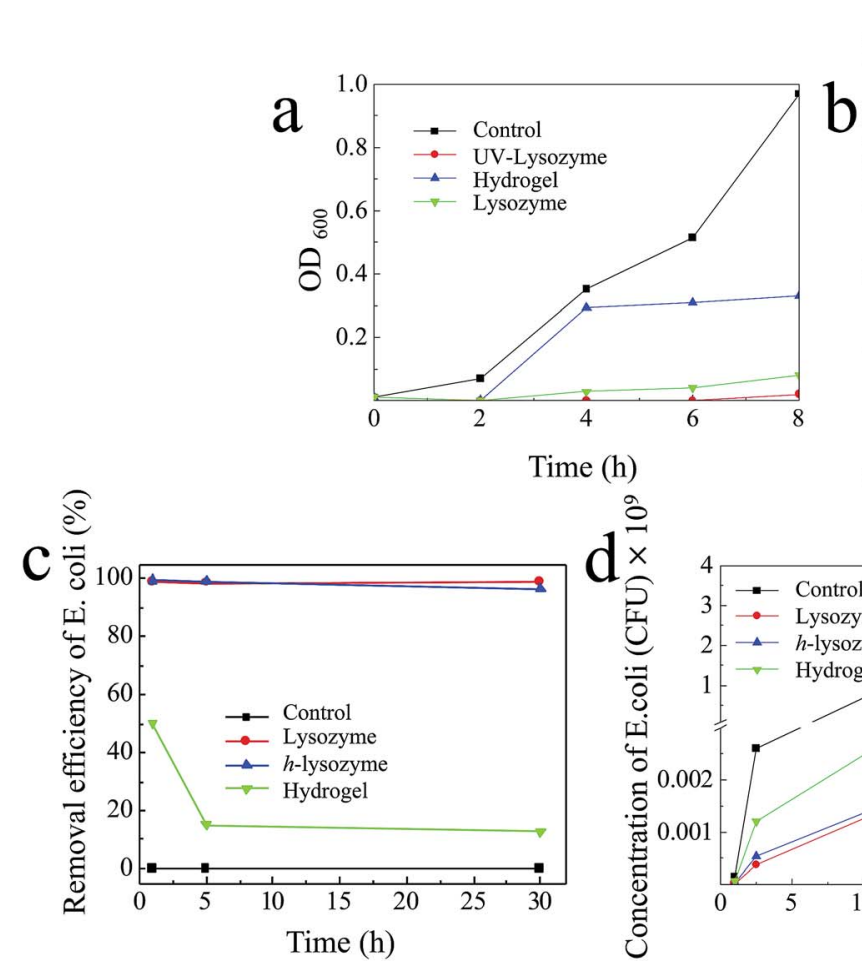

$\stackrel{8}{=}$
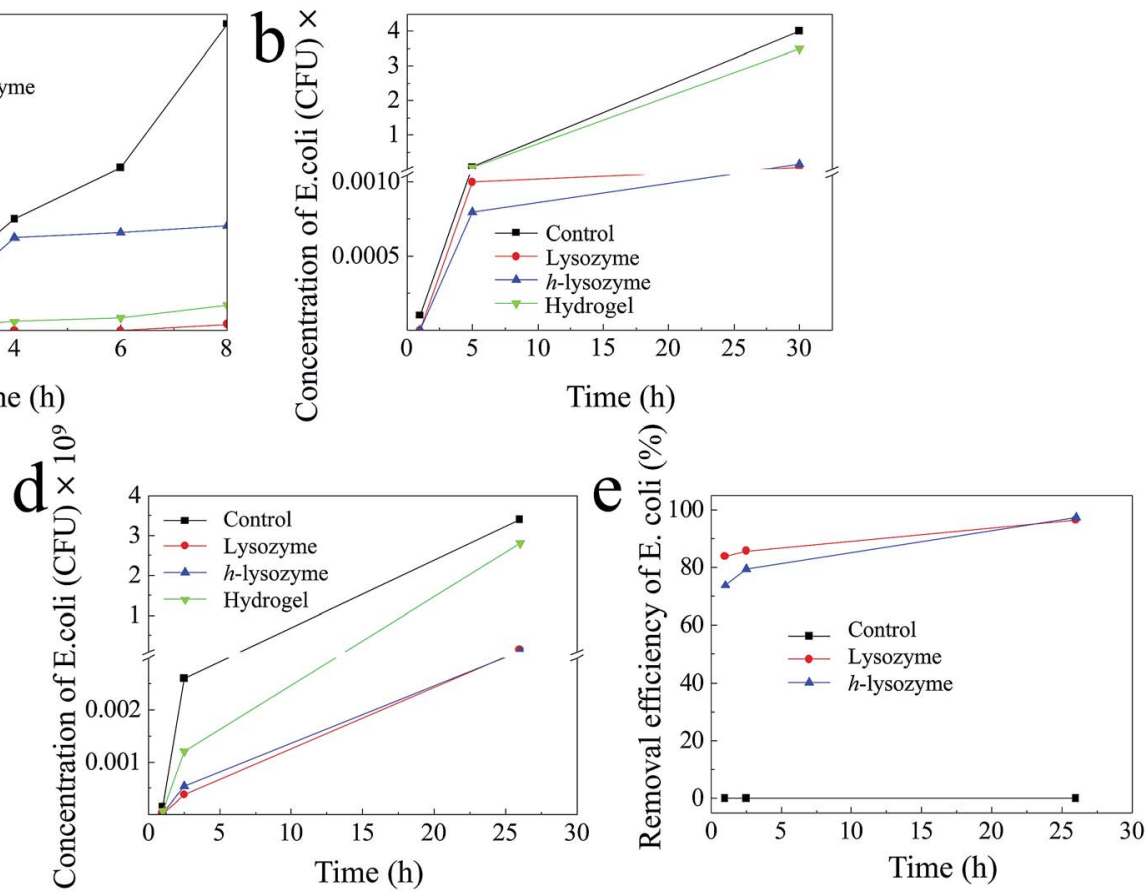

Fig. 4 The antibacterial results with different samples. (a) $O D_{600}$ regrowth curves of $E$. coli bacteria exposed to different samples (blank as control, $3.2 \mathrm{mg} \mathrm{mL}^{-1} \mathrm{UV}$ irradiated lysozyme, blank hydrogel and $3.2 \mathrm{mg} \mathrm{mL}^{-1}$ lysozyme) at $37^{\circ} \mathrm{C}$ for $8 \mathrm{~h}$. (b) The concentration of $E$. coli in DI water $\left(10^{5} \mathrm{CFU}\right.$ initial concentration) after treatment with $3.2 \mathrm{mg} \mathrm{mL}^{-1}$ lysozyme, blank hydrogel and h-lysozyme, the natural E. coli as control. (c) The calculated removal efficiency of $E$. coli after treatment with $3.2 \mathrm{mg} \mathrm{mL}^{-1}$ lysozyme, blank hydrogel and h-lysozyme. (d) The concentration of E. coli in DI water $\left(10^{5} \mathrm{CFU}\right.$ initial concentration) after treatment with $1 \mathrm{mg} \mathrm{mL}^{-1}$ lysozyme, blank hydrogel and h-lysozyme, the $E$. coli as control. (e) The calculated removal efficiency of $E$. coli after treatment with $1 \mathrm{mg} \mathrm{mL}^{-1}$ lysozyme, blank hydrogel and h-lysozyme.

similar to that of pure lysozyme (Fig. 4b). The E. coli inhibition efficiency was calculated based on the measured concentration vs. the control concentration (Fig. 4c). The inhibition efficiencies of h-lysozyme and lysozyme were $99.4 \%$ and $99.0 \%$ in the first hour and they were still $96.3 \%$ and $98.8 \%$ after 30 hours, respectively. The E. coli inhibition with a low lysozyme concentration of $1 \mathrm{mg} \mathrm{mL} \mathrm{mL}^{-1}$ was also studied, as shown in Fig. 4d. As can be seen from the figure, h-lysozyme shows the best inhibition performance in contrast to pure lysozyme, hydrogel or control samples. The inhibition efficiency of $h$ lysozyme after 26 hours was as high as $97.3 \%$, which is higher than that of pure lysozyme of $96.4 \%$ (Fig. 4e), indicating promising potential in long-term antibacterial capability.

In order to expand the antibacterial applications, the Grampositive bacteria Bacillus subtilis (B. subtilis) in water were also tested. ${ }^{30,40}$ As shown in Fig. 5a, h-lysozyme exhibited the lowest
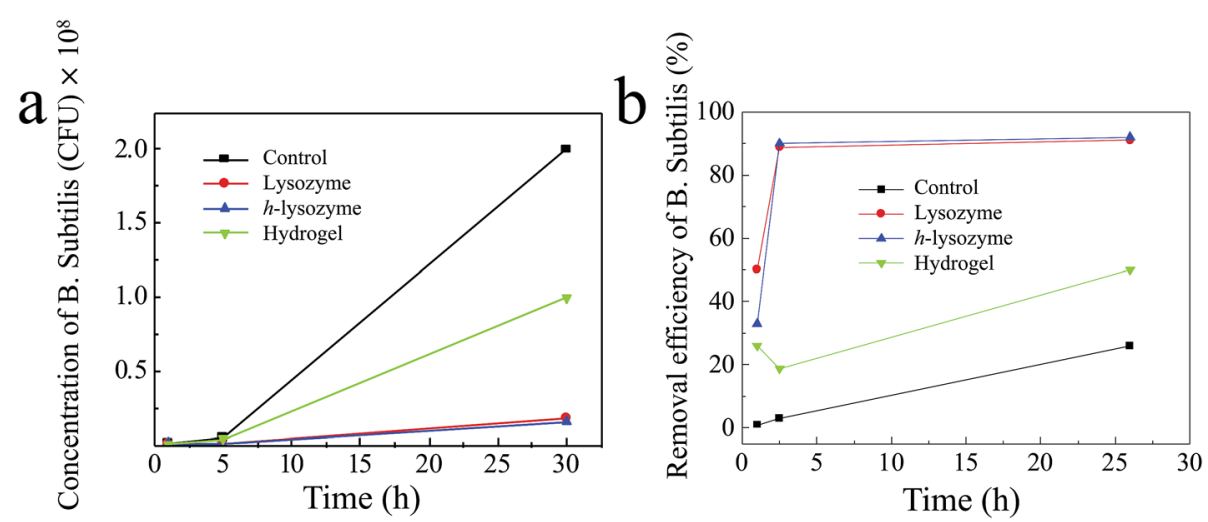

Fig. 5 (a) Concentration evolution of $B$. subtilis in DI water ( $10^{5}$ CFU initial concentration) after treatment with $3.2 \mathrm{mg} \mathrm{mL}^{-1}$ lysozyme, blank hydrogel and h-lysozyme, the natural $B$. subtilis as control. (b) The removal efficiency of $B$. subtilis after treatment with $3.2 \mathrm{mg} \mathrm{mL}^{-1}$ lysozyme, blank hydrogel and h-lysozyme and $B$. subtilis as control. 
concentration, $1.6 \times 10^{7} \mathrm{CFU} \mathrm{mL}^{-1}$, of bacteria after 30 hours (blue). A corresponding inhibition efficiency of $>92 \%$ after 26 hours was achieved (Fig. 5b), enabling better antibacterial durability.

In this work, we successfully developed a hydrogelimmobilized lysozyme that showed greatly improved antibacterial capability with high inhibition activity, wide concentration and temperature ranges and long recycling performance in drinking water. The increased interfaces between the lysozyme and bacteria molecules due to the large surface area from the porous structure of the hydrogel improve the inhibition of both Gram-negative and Gram-positive bacteria such as E. coli and $B$. subtilis. In addition, the industrial availability and non-toxicity of the lysozyme with hydrogel provide a promising alternative to the existing silver-based antibacterial catalysts for drinking water treatment.

\section{Conflicts of interest}

There are no conflicts to declare.

\section{Acknowledgements}

All authors acknowledge the support from industry partners.

\section{Notes and references}

1 J. W. Patterson, Industrial Wastewater Treatment Technology, Butterworth-Heinemann, 1985, ISBN-13: 978-0409900026.

2 R. A. Crane and T. B. Scott, J. Hazard. Mater., 2012, 211, 112125.

3 M. N. Chong, B. Jin, C. W. K. Chow and C. Saint, Water Res., 2010, 44, 2997-3027.

4 M. A. Shannon, P. W. Bohn, M. Elimelech, J. G. Georgiadis, B. J. Marinas and A. M. Mayes, Nanosci. Technol., World Scientific, 2010, pp. 337-346.

5 J. Lalley, D. D. Dionysiou, R. S. Varma, S. Shankara, D. J. Yang and M. N. Nadagouda, Curr. Opin. Chem. Eng., 2014, 3, 25-29.

6 T. Shintani, H. Matsuyama and N. Kurata, Desalination, 2007, 207, 340-348.

7 T. Kawaguchi and H. Tamura, J. Appl. Polym. Sci., 1984, 29, 3359-3367.

8 L. Duan, Y. Wang, Y. Zhang and J. Liu, Appl. Surf. Sci., 2015, 355, 436-445.

9 J. Hankiewicz and E. Swierczek, Clin. Chim. Acta, 1974, 57, 205.

10 B. Porstmann, K. Jung, H. Schmechta, U. Evers, M. Pergande, T. Porstmann, H. Kramm and H. Krause, Clin. Biochem., 1989, 22, 349.

11 J. Wang, L. Tang, P. Somasundaran, W. Fan, G. Zeng, Y. Deng, Y. Zhou, J. Wang and Y. Shen, J. Colloid Interface Sci., 2017, 503, 131-141.

12 S. Bel, M. Pendse, Y. Wang, Y. Li, K. A. Ruhn, B. Hassell, T. Leal, S. E. Winter, R. J. Xavier and L. V. Hooper, Science, 2017, 357, 1047-1052.

13 D. Saeki, S. Nagao, I. Sawada, Y. Ohmukai, T. Maruyama and H. Matsuyama, J. Membr. Sci., 2013, 428, 403-409.
14 J. Wang, L. Qin, J. Lin, J. Zhu, Y. Zhang, J. Liu and B. Van der Bruggen, Chem. Eng. J., 2017, 323, 56-63.

15 T. Wu, C. Wu, S. Fu, L. Wang, C. Yuan, S. Chen and Y. Hu, Carbohydr. Polym., 2017, 155, 192-200.

16 C. Liu, L. Chen and L. Zhu, Water Res., 2017, 119, 33-46.

17 C. Mateo, J. M. Palomo, G. Fernandez-Lorente, J. M. Guisan and R. Fernandez-Lafuente, Enzyme Microb. Technol., 2007, 40, 1451-1463.

18 P. Appendini and J. H. Hotchkiss, Packag. Technol. Sci., 1997, 10, 271-279.

19 L. Wilson, A. Illanes, B. C. C. Pessela, O. Abian, R. Fernández-Lafuente and J. M. Guisán, Biotechnol. Bioeng., 2004, 86, 558-562.

20 V. Figueira, I. Vaz-Moreira, M. Silva and C. M. Manaia, Water Res., 2011, 45, 5599-5611.

21 T. Su, Z. Tang, H. He, W. Li, X. Wang, C. Liao, Y. Sun and Q. Wang, Chem. Sci., 2014, 5, 4204-4209.

22 G. Lesnierowski, J. Kijowski and R. Cegielska-Radziejewska, J. Food Sci. Technol., 2009, 44, 305-311.

23 Q. Z. Yang, Y. Y. Chang and H. Z. Zhao, Water Res., 2013, 47, 6712-6718.

24 M. Yuceer and C. Caner, J. Sci. Food Agric., 2014, 94, 153-162. 25 A. Zimoch-Korzycka and A. Jarmoluk, J. Food Sci. Technol., 2015, 52, 5996-6002.

26 H. Yuk, T. Zhang, S. Lin, G. A. Parada and X. Zhao, Nat. Mater., 2016, 15, 190.

27 T. Su, D. Zhang, Z. Tang, Q. Wu and Q. Wang, Chem. Commun., 2013, 49, 8033-8035.

28 Q. Zhao, C. Liu, J. Liu and Y. Zhang, $R S C A d v ., 2015,5$, 38646-38653.

29 T. Wu, J. Huang, Y. Jiang, Y. Hu, X. Ye, D. Liu and J. Chen, Food Chem., 2018, 240, 361-369.

30 N. R. Srinivasan, P. A. Shankar and R. Bandyopadhyaya, Carbon, 2013, 57, 1-10.

31 D. M. Chipman and N. Sharon, Science, 1969, 165, 454-465.

32 H. A. McKenzie and F. H. White, Adv. Protein Chem., 1991, 41, 173-315.

33 A. Malzert, F. Boury, D. Renard, P. Robert, J. E. Proust and J. P. Benoît, Int. J. Pharm., 2002, 242, 405-409.

34 M. van de Weert, J. Hoechstetter, W. E. Hennink and D. J. A. Crommelin, J. Controlled Release, 2000, 68, 351-359.

35 S. I. Park, M. A. Daeschel and Y. Zhao, J. Food Sci., 2004, 69, M215-M221.

36 F. Zhang, Y. Y. Zhao, H. Chen, X. H. Wang, Q. Chen and P. G. He, Chem. Commun., 2015, 51, 6613-6616.

37 Q. Wang, Q. Gao and J. Shi, J. Am. Chem. Soc., 2004, 126, 14346-14347.

38 S. Priyadarshini and V. K. Kansal, J. Dairy Res., 2002, 69, 419431.

39 Y. Ye, L. Xiao, B. He, Q. Zhang, T. Nie, X. Yang, D. Wu, H. Cheng, P. Li and Q. Wang, J. Mater. Chem. B, 2017, 5, 1518-1524.

40 J. A. M. Delezuk, D. E. Ramírez-Herrera, B. E. F. de Ávila and J. Wang, Nanoscale, 2017, 9, 2195-2200. 